\title{
Reanalysis of the Anthrax Epidemic in Rhodesia, 1978-84
}

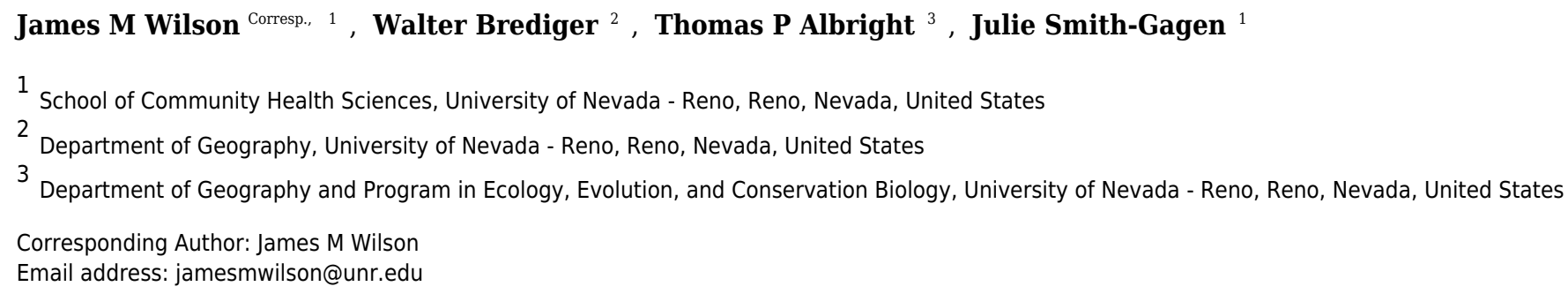

In the mid-1980s, the largest epidemic of anthrax of the last 200 years was documented in a little known series of studies by Davies in The Central African Journal of Medicine. This epidemic involved thousands of cattle and 10,738 human cases with 200 fatalities in Rhodesia during the Counterinsurgency. Grossly unusual epidemiological features were noted that, to this day, have not been definitively explained. This study performed a historical reanalysis of the data to reveal an estimated geographic involvement of 245,750 $\mathrm{km}^{2}$, with 171,990 cattle and 17,199 human cases. Here we present the first documented geotemporal visualization of the human anthrax epidemic. 
1 Reanalysis of the Anthrax Epidemic in Rhodesia, 1978-84

2

3 James $\mathrm{M}$ Wilson, $\mathrm{MD}^{1^{*}}$, Walter Brediger ${ }^{2}$, Tom Albright, $\mathrm{PhD}^{3}$, and Julie Smith-Gagen, $\mathrm{PhD}^{1}$

4

5 1. School of Community Health Science, University of Nevada-Reno

62 2. Department of Geography, University of Nevada-Reno

7 3. Department of Geography and Program in Ecology, Evolution, and Conservation Biology,

$8 \quad$ University of Nevada-Reno

9

10

11

12

13

14

15

16

17

18

19

20

21

22

23

24

* Division of Health Sciences, 1664 North Virginia Street, Reno, NV 89557-0136; jamesmwilson@unr.edu 


\section{ABSTRACT}

26

27 In the mid-1980s, the largest epidemic of anthrax of the last 200 years was documented in a little known 28 series of studies by Davies in The Central African Journal of Medicine. This epidemic involved 29 thousands of cattle and 10,738 human cases with 200 fatalities in Rhodesia during the Counterinsurgency.

30 Grossly unusual epidemiological features were noted that, to this day, have not been definitively

31 explained. This study performed a historical reanalysis of the data to reveal an estimated geographic 32 involvement of $245,750 \mathrm{~km}^{2}$, with 171,990 cattle and 17,199 human cases. Here we present the first 33 documented geotemporal visualization of the human anthrax epidemic.

34

35

36

37

\section{INTRODUCTION}

Anthrax is a potentially lethal disease caused by Bacillus anthracis, an aerobic spore-forming bacterium that exists in a complex ecological cycle predominantly involving herbivorous mammals and man. Persistence of anthrax in the environment is due to soil borne spores that remain viable for decades. It is an Office International des Epizooties (OIE) List B disease, for which obligatory reporting is requested of all OIE Member States. The ancient origin of Bacillus anthracis is sub-Saharan Africa, specifically the region encompassing Kruger National Park and the North Cape Province of South Africa. Over the centuries, anthrax has been exported throughout the world predominantly through the trade of domestic herbivores. ${ }^{1}$

Anthrax was first recognized in colonial times in southern Africa in 1842 and was placed on the list of scheduled diseases in South Africa in 1891. Europeans noted the persistent spread of anthrax in their cattle herds and eventually pushed for control programs that yielded the development of vaccines from 1920 onward. In 1923, South Africa had reported the death of 30,000-60,000 cattle, however once 
51 vaccination was initiated, a dramatic reduction in bovine anthrax was noted. The culmination of an

52 effective vaccination program in South Africa was realized with the Sterne vaccine in 1937, where

53 knowledge of South Africa's success in controlling anthrax was shared with Rhodesia, now known as the

54 country of Zimbabwe. ${ }^{1,2}$

55

56 In 1978, during the context of the Rhodesian Counterinsurgency, an unprecedented anthrax epidemic in

57 livestock and humans began in Rhodesia. The epidemic progressed largely unchecked until the mid-

58 1980s as the largest known anthrax epidemic in history. This event was documented by Davies in a three-

59 part descriptive study from 1982 to 1985 that was limited to three of five involved provinces ${ }^{3-5}$.

60 Additional primary source documentation was limited that provided greater insight into the location, case

61 count, spread, and etiology of this epidemic.

62

63 A total of 10,738 human cases and approximately 200 deaths (1.9\% fatality rate) were reported by JCA

64 Davies in The Central African Journal of Medicine across Midlands, Matabeleland, and Mashonaland

65 Provinces from January 1979 through December 1980. The majority of reported human cases were the

66 cutaneous form of the disease, however all known clinical forms of anthrax infection were documented

67 during the course of the epidemic. The universally acknowledged source of human cases was cattle

68 infected in rural, noncommercial farming areas known as Tribal Trust Lands. ${ }^{3-5}$ The majority, if not all of

69 the cases were among indigenous African farmers living on Tribal Trust Lands. This was an important

70 observation given that approximately $85 \%$ of the country was considered agricultural land, of which half

71 was Tribal Trust Lands. ${ }^{6}$ Because of the extent of agricultural land involved, the epidemic was described

72 as "an economic disaster".

73

74 The two primary agricultural land classifications of Rhodesia in the late 1970s were Tribal Trust Lands

75 and commercial farming areas. Tribal Trust Lands covered 16.4 million hectares of rural Rhodesia and

76 were designated by the government for subsistence agriculture by indigenous ethnic groups. These areas 
77 were known to be of generally marginal agricultural value because of climatic conditions (sporadic

78 rainfall and lengthy droughts), soil quality, and farmers' lack of resources (e.g., lime) to improve and

79 maintain soil quality. Over 4 million people lived in the Tribal Trust Lands, 800,000 of them belonging to

80 indigenous African farming families; this represented the majority of the rural indigenous population of

81 the country at twice the population density of the Europeans living on the commercial agricultural areas.

82 The majority of cattle raised on the Tribal Trust Lands were used for agricultural labor, personal

83 consumption, trade, and sources of fertilizer. Commercial agricultural areas included farms owned by

84 European farmers who raised cattle for profit, as well as tobacco and other cash crops. The land

85 appropriated for these farms was roughly equal in size to the Tribal Trust Lands and was located in fertile 86 areas. ${ }^{6,8,9}$

87

African lineages of cattle were comprised of Mashona, Matabele, Zansi, Amabula, Kavuvu, Amabowe types and had been present in Rhodesia since at least the early 1800 s, which was the limit of documented history in this region of the world. Cattle were an integral part of migrant indigenous peoples of the period. ${ }^{2}$ Loosely considered, the African lineages resided on the Tribal Trust Lands, whereas the European lineages resided on commercial agricultural lands.

Prior to 1960, Rhodesians had destroyed much of the indigenous wildlife during the expansion of cattle ranching. However, after 1960, concerted effort was directed to the re-establishment of game and wildlife

97 both on private ranches and in national parks. Private ranches engaged in profitable trade with the

98 tanning industry, where elephant, antelope, and zebra skins garnered the bulk of the industry's income in 99 the mid-1970s. ${ }^{10}$

101 Prior to the war, the national anthrax control program was considered one of the most advanced and 102 effective in Africa. This was a program that had been in place since approximately the mid-1950s. 
103 During the war, vaccination for anthrax was maintained largely on commercial as opposed to Tribal Trust

104 Land farms due to chronic distrust of indigenous Africans directed towards European veterinary practice. ${ }^{2}$

105 The disruption of standard veterinary services on the Tribal Trust Lands during the war was associated

106 with a dramatic resurgence of multiple diseases in cattle, such as various tick-borne diseases,

107 trypanosomiasis, rabies, and two outbreaks of vaccine-resistant hoof-and-mouth disease. ${ }^{3,11}$

108

109 Anthrax was rare in Rhodesia prior to 1978, as shown in Figure 1. In 1898, 41 cattle died of anthrax in

110 Matabeleland Province, which was the first documented appearance of anthrax in Rhodesia. In 1912, 14

111 pigs and one donkey in Ardbennie and six cattle in Umganin, Bulawayo, died of anthrax. At Mount

112 Hampden, nine cattle died in a limited outbreak in 1917. A larger epidemic in Shamva two years later

113 resulted in the deaths of 102 head of cattle on 18 farms. In 1920, 18 cattle died in Hartley, Mtoko, and

114 Shamva. All of these outbreaks were in western Rhodesia, north of Hartley. ${ }^{12}$ Other limited outbreaks in

115 bovines and humans were reported in Chipinga (1952-54), Mhondoro Tribal Trust Land (1974), and

116 Mount Darwin (1965 and 1970-71).3,5,11,13,14 There were 6 human cases and 2 deaths reported in the

117 Mhondoro outbreak; the high fatality rate was attributed to delays in seeking timely medical attention. ${ }^{8}$

118 Data on human cases were unavailable for the Chipinga and Mount Darwin outbreaks. No outbreaks of

119 anthrax were documented in Rhodesian wildlife until 2004. ${ }^{15}$

120

121 FIGURE 1. Historical anthrax human cases and fatalities reported from 1926 to 1977 . Vaccination for

122 anthrax in cattle was not available until the mid-1950s.

123

124 Human anthrax was rare, as Davies noted, "the majority of doctors in Rhodesia had never seen a case of

125 anthrax". 5 The majority of reported human cases in these earlier outbreaks were cutaneous and, to a

126 much lesser degree, gastrointestinal; infections were acquired from handling or eating infected livestock. ${ }^{3-}$

$127{ }^{5}$ The approximate annual number of human cases reported nationally was 6 per year, for a total of 322

128 cases and 20 fatalities from 1926 to $1977 .^{3}$ 
130 The purpose of this study was to re-examine the 1979-80 anthrax epidemic in Rhodesia in light of new

131 data and analytic insights gained in the years since this important event.

132

133

134 MATERIALS AND METHODS

135

136 We conducted literature searches using PubMED (United States National Library of Medicine) and

137 AGRICOLA (United States National Agricultural Library) for all references to anthrax in southern Africa

138 from 1970 to the present. We also reviewed all available veterinary and agricultural literature published

139 in Rhodesia from 1975 to 1985 . Historical land classification maps published for Rhodesia from 1975 to

1401981 were obtained from the United States Library of Congress ${ }^{16}$. All available original manuscripts

141 regarding anthrax in Rhodesia were reviewed, and a reanalysis of the epidemiological data contained

142 therein was performed. We examined references to epidemic features such as historical (pre-epidemic)

143 data, route of infection, severity of disease, meteorological data and seasonality, host animals, potential

144 vectors, and vaccination coverage. The sources of these different aspects of the epidemic are referenced

145 in the results section.

146

147 World Meteorological Organization archival average temperature and precipitation data for Rhodesia was 148 used to assess meteorological anomalies for $1977-1980^{17}$. Anomalies were calculated using the following 149 equation:

150

151 anomaly $=($ monthly value - monthly average $) /$ monthly standard deviation;

152

153 Where monthly data for 1901 to 1976 was used to calculate the monthly average and standard deviation. 154 
155 In order to assess the spread of anthrax outbreaks in Rhodesia in space and time, we performed a simple

156 geospatial analysis using ArcGIS [ESRI, Redlands, CA, USA]. We defined an "outbreak" as an incipient

157 focus of human anthrax cases that appeared in a district level hospital, which was the finest spatial

158 resolution available in the data. The month and year of first cases reported to these district hospitals was

159 the only data available; continuous monthly times series case counts were not available. We

160 georeferenced hospital locations using Wikipedia [https://www.wikipedia.org] and Google Maps

161 [https://www.google.com/maps]. Because nearly all of the human anthrax cases followed contact with

162 cattle exhibiting signs of anthrax infection, we investigated the availability of bovine anthrax data from

1631978 to 1980 . We were unable to identify any surviving record of bovine anthrax data for this time

164 period. $^{18}$

165

166 To evaluate JCA Davies' description of contiguous and non-contiguous geotemporal spread, we then

167 calculated the centroid (arithmetic mean) of outbreak locations for each time step in our series.-5

168 Geospatial cluster analysis was performed using the Kulldorff space-time permutation model resident in

169 SaTScan v9.4 $4^{19,20}$, where the objective was to statistically identify space-time clusters such as reports of

170 multiple waves of human cases within the context of the epidemic itself. Default settings were used for

171 the analysis to allow for identification of possible seasonal patterns.

172

173

174 RESULTS

175

176 First recognition of the epidemic was in Nkai District, Matabeleland Province, November 1978, with a

177 low number of human cases reported until June 1979. All of the cases were associated with the

178 butchering and skinning of local cattle. Nkai Hospital would later report over 500 cases from January

1791979 to October 1980, which was 1.5 times that of all human cases reported from 1926 to 1977.

180 Approximately half of these cases required hospitalization, with 17 fatalities (case fatality rate $3.3 \%$ ). 
181 Eight of the fatalities were due to respiratory anthrax (47\%). The remainder died of sepsis that followed a 182 cutaneous lesion. This was considered the first phase of the epidemic. ${ }^{3-5}$

183

184 The epidemic smoldered until mid-1979, when a second phase of the epidemic was apparent. Case

185 counts abruptly increased from September to November 1979 (Figure 2) ahead of the rainy season peak in

186 December-January (Figure 3). ${ }^{17}$ While extreme meteorological phenomena were not reported previous to

187 or during the time period of the epidemic, higher than normal precipitation occurred in early 1978 (Figure

188 4). ${ }^{17}$ Geotemporal variation in epidemic progression was observed at the provincial level (Figure 5),

189 where epidemic peaks were sequential across Matabeleland (November 1979), Midlands (December

190 1979), and Mashonaland Provinces (February 1980). Midlands Province was noted to begin peaking in

191 October 1979 (Figure 6). ${ }^{3-5}$ This was suggestive of a general southwest to northeast progression. The

192 patients were dominantly Tribal Trust Land inhabitants, with rare documentation of cases among those in

193 the tanning industry.4, 5 Over the course of five months (November 1979 to March 1980), explosive

194 spread of anthrax in Mashonaland Province had encompassed 13 districts and $120,000 \mathrm{~km}^{2}$. $3-5$

195

196

FIGURE 2. Rhodesian human anthrax cases and fatalities from January 1979 to December 1980 for the provinces of Matabeleland, Midland, and Mashonaland.

198

FIGURE 3. Average annual Rhodesia climatology based on data from 1960-80. A dramatic surge in

199 human cases was observed ahead of the peak of the rainy season. Arrows indicate the start of the first (yellow) and second (red) phases of the human epidemic, in November 1978 and September 1979, respectively.

FIGURE 4. Monthly temperature and precipitation anomalies for Rhodesia, 1977-1980. Anomaly calculations used data from 1901-1976 (see Materials and Methods). Arrows indicate the start of the first 204 (yellow) and second (red) phases of the human epidemic, respectively. 
FIGURE 5. Human anthrax cases by province, noting the temporal shift in the peak of cases as the epidemic progressed across the country. A second wave of cases is observed in the data for Mashonaland Province. October 1979 to February 1980.

211 The Beatrice Road Infectious Diseases Hospital, located in Salisbury (now called Harare), saw 712 cases

212 from January 1980 to June 1982 (Figure 7). These patients were referred to the hospital from across

213 Mashonaland Province. All were Tribal Trust Land inhabitants except one individual from a tanning

214 facility. Resource strain at the hospital was reflected in demand for hospitalizations, as noted in February

2151980 and December 1980, which was the result of two waves of patients who were hospitalized for two to 216 five weeks. By March 1980, the Beatrice Road Infectious Diseases Hospital reported that the most 217 common reason for admission to their hospital was anthrax. The number of cases seen at Beatrice Road 218 was considered enough to prompt concerns about contamination of the hospital with anthrax spores, 219 which resulted in heavy use of masks, gowns and gloves until supplies were unable to meet the demand. 220 However, no infection was noted among healthcare providers or between patients. Although many 221 medical facilities reported abrupt, significant strain on their resources, fatality rates were considered very 222 low and manageable. There was no report of antimicrobial resistance; rather, the vast majority of the 223 patients were effectively managed with penicillin. There was no indication of a penicillin shortage. ${ }^{5}$

FIGURE 7. Human anthrax cases seen at the Beatrice Road Infectious Disease Hospital. This hospital, by March 1980, reported that anthrax was the leading reason for hospital admission. The facility experienced resource strain in two periods that coincided with two waves of patients in February 1980 229 and again in December 1980. 
230 Inhalation, gastrointestinal, and meningitis presentations were documented at the Beatrice Road

231 Infectious Diseases Hospital as well as additional hospitals. ${ }^{3}$ Five cases of anthrax meningitis, all fatal, 232 out of 18 total cases seen were reported over the course of 12 months at Parirenyatwa General Hospital, 233 also in Salisbury. This facility had not previously seen a single case of anthrax from 1970 to mid-1979.

234 All of these fatal cases had cutaneous lesions that followed contact with cattle upon presentation. Several 235 of these cases had reported a painful insect bite that preceded development of the classic anthrax eschar

236 lesion. Death was observed within one week of initial symptoms. This experience prompted several case 237 report publications because these presentations had previously been "extremely rare" in Rhodesia. ${ }^{5,21-23}$

238 The unusual volume and variety of clinical presentations led to comparisons at the time to the Sverdlovsk, 239 U.S.S.R. outbreak of anthrax. ${ }^{7}$ The Sverdlovsk outbreak was later shown to be an accident of a biological 240 weapons laboratory. ${ }^{24}$

241

242 Figure 8 displays where human cases were first recognized, at the finest temporal and spatial resolution 243 the epidemiological data allowed (i.e. monthly and district hospital coordinate). Time series data for case 244 counts for district level hospitals was unavailable; therefore data regarding multiple epidemic waves seen 245 for a given hospital was unavailable with the exception of the Beatrice Road Infectious Disease Hospital 246 (Figure 7). After June 1979, the epidemic spread eastward to Que Que District, Midlands Province, then 247 erratically in the context of a "puzzling hop[ping]" phenomenon, whereby anthrax cases appeared in 248 multiple foci with non-contiguous involvement of the land between. ${ }^{3}$ We attempted to further elucidate 249 the hopping phenomenon by using a combination of centroid distance measurements and the Kuldorff 250 statistic. The Kuldorff space-time permutation highlighted four clusters of non-significant, but increased 251 relative risk for high anthrax activity as shown in Table 1 and displayed in Figure 8. The map 252 corresponding to November 1979 in Figure 8 is an example of a hop, which involved non-contiguous 253 spread to Filabusia, Umzingqane, and Bembezi Districts from Nkai and Que Que Districts. Another 254 example of a hop was in March 1980, with spread to Chilimanze, Charter, and Seluweke. These hops 255 involved distances of 40-50 km. According to Davies, "The intervening commercial and communal areas 
256 did not report any cases at this time." The context of these observations was during the second phase of 257 the epidemic, when explosive spread was noted to involve 120,000 $\mathrm{km}^{2}$ within 5 months in Mashonaland 258 Province. $^{3}$

259

260

FIGURE 8. Geospatial time series progression of the anthrax epidemic in humans. The mean of outbreak coordinates is indicated as a centroid coordinate, where each time step is associated with spatial movement of that coordinate. Only time steps associated with the first human cases for each site are shown. Geotemporal clusters associated by the Kuldorff statistic with higher relative risk for high anthrax case counts are shown and denoted with a capital letter (A-D). According to Davies, the spread of anthrax in humans involved a non-contiguous, heterogeneous distribution pattern.

TABLE 1. Results of the Kuldorff space-time permutation analysis. Statistical significant was defined by $\mathrm{P}<0.05$. The clusters identified were associated with non-significant, higher relative risk. ${ }^{19}$

269

270 Up to the point of the epidemic, an average of 20 cases were seen in livestock annually. ${ }^{11}$ In the pre-1980

271 time period, systematic animal disease surveillance was not performed, especially on the Tribal Trust

272 Lands. The epidemic among humans began nearly exclusively through contact with cattle across all areas

273 of involvement in Rhodesia. In Lupane, within the epicenter, more than 5,000 head of the total cattle

274 population (5\%) had died. ${ }^{11,25}$ National statistics for the total number of anthrax-related cattle deaths from 275 1979-1980 were unavailable, but one report cited "many thousands". ${ }^{11}$ Up to 50\% of cattle herds died in 276 some communities. ${ }^{26}$ After conducting a full literature review, we were unable to document reports of 277 anthrax in any of the neighboring countries during the time of the Rhodesia epidemic. There was no 278 report of any other animal species involved in the epidemic, with the exception of the rare, occasional 279 domestic goat ${ }^{25}$. The first documented appearance of anthrax in the wildlife of Zimbabwe was in 2004. ${ }^{15}$

280 Because no point source could be identified, introduction of anthrax to cattle via feed or fertilizer was 
281 hypothesized, however rejected in favor of emergence from endemic foci. ${ }^{25}$ Access to safe drinking water 282 on the Tribal Trust Lands for both humans and cattle became a serious concern. ${ }^{4}$

283

284 Chikerema et al recently examined archival bovine anthrax data for Zimbabwe dating back to $1967^{27}$,

285 however acknowledged there was no data on bovine anthrax for the period examined in this study ${ }^{18}$.

286 From 1967 to 1976, 12 districts had reported bovine anthrax, followed by dramatic expansion to 42

287 districts by 2006. The majority of bovine anthrax continues to be documented in rural areas. As of 2006,

288 one of the districts associated with the highest risk of bovine anthrax activity was also identified by this

289 study as higher relative risk, but not statistically significant, as Cluster $\mathrm{A}(\mathrm{P}=0.24)$. This likely reflects a

290 difference in anthrax zones in the late 1970s versus expansion of anthrax zones observed by 2006.

291

292 Chikerema et al also identified seasonality at the national level in bovine anthrax activity where a peak

293 was noted in October that coincides with peaking seasonal temperature and the beginning of the rainy

294 season (Figure 3). ${ }^{27}$ Figure 2 shows the approximate national view of the human case counts summarized

295 over three of the five provinces that reported cases. The cases peaked in November, the majority of

296 which followed contact with infected cattle. The epidemic began in humans in November 1978. The

297 Beatrice Road Infectious Disease Hospital had observed two waves of patients, in February and

298 December, respectively. The Kuldorff statistical analysis identified November 1978 (Cluster A, P=0.24),

299 September 1979 (Cluster $\mathrm{B}, \mathrm{P}=0.055$ ), and January and February 1980 (Clusters $\mathrm{C}$ and $\mathrm{D}, \mathrm{P}=0.25$ and

3000.79 , respectively). Our findings suggest higher relative risk for human anthrax cases followed the period

301 identified by Chikerema et al as seasonal peaking bovine anthrax activity.

302

303 During the course of the epidemic, veterinary control measures had waned in the context of the Rhodesian

304 Counterinsurgency. Anthrax vaccines were acquired in response to the epidemic, but supply was

305 limited. ${ }^{11}$ The response campaign was considered ineffective due to poor utilization by the effected

306 communities, due to pressure from insurgent forces to not cooperate with the national veterinary service. 
$307{ }^{26}$ After the war in 1981, vaccination services resumed and reached $70 \%$ of the national cattle herd by

308 1985. ${ }^{11}$ Despite re-establishment of control, bovine anthrax activity continued to expand dramatically to $3092006 .^{27}$

310

311 Substantial underreporting of human cases by as much as 50\% was inferred given the number of district

312 hospitals and medical facilities who responded to Davies' survey and the likelihood that many patients

313 either chose not to be evaluated by a medical facility or did not survive long enough for evaluation, as

314 was observed in prior anthrax outbreaks in Rhodesia., ${ }^{3,13}$ Ongoing conflict over much of the anthrax-

315 involved areas also impeded communications. ${ }^{28}$ This represents an important source of potential bias

316 when examining the results of the space-time permutation model described above.

317

318 We found that Davies' text description of the total human cases equating to 10,738 to be in discrepancy

319 with the epidemiological data presented in his manuscripts' tables for Midlands, Matabeleland, and

320 Mashonaland Provinces from January 1979-December 1980, which collectively reported a total of 17,068

321 cases and 101 fatalities. $^{3}$ In terms of overall case counts for the epidemic, we found this to underestimate

322 the true extent of the epidemic as well, given:

323 - Data reported by Davies did not include summary statistics for the involved areas of Manicaland

324 and Victoria Provinces, however was briefly discussed in his Beatrice Road manuscript; ${ }^{3-5}$

325 - Beatrice Road Infectious Diseases Hospital in Harare, Mashonaland Province reported 131

326 additional cases and 4 fatalities (0.03\% fatality rate) from January 1981-June 1982; 5

327 Kubuch et al reported anthrax cases in Lupane extending through $1984 ; ;^{25}$ and

328 - Statistics reported by Davies for Mashonaland Province indicated a second epidemic peak in

329 December 1980 without evidence of transmission resolution (i.e. incomplete data). ${ }^{3-5}$

330 
331 Based on inclusion of this new data we found an overall discrepancy of 10,738 versus 17,199 cases and 332 over 200 fatalities versus 105 fatalities if only the data tables from Davies' manuscripts are considered.

333 We were unable to account for those patients on the rural Tribal Trust Lands who were infected, unable to 334 seek appropriate medical care, and be documented in the epidemiological reports. A larger number of 335 subclinical cases and exposures were likely based on observations of the low relative infectivity of 336 anthrax spores in humans. ${ }^{29}$ Compared to annual baselines prior to this epidemic, this was at least more 337 than 1,400 times above expected annual baselines in the half-century prior to this epidemic. Based on the 338 observation that the majority of these human cases were Tribal Trust Land residents, we estimate the 339 attack ratio to have been 17,199 cases in the rural farming population of $800,000(2.1 \%)$ versus the 340 overall Tribal Trust Land population of at least 4 million (0.43\%). Based on an estimated 1 human 341 cutaneous case to 10 infected cattle carcasses, we estimate the true number of infected cattle to be $342171,990 .{ }^{29}$ When attempting to discern the duration of the event, it is apparent the epidemic began in 343 November 1978 and extended beyond 1980, to at least December 1984. This too raises questions 344 regarding additional unreported cases that occurred beyond the purview of Davies' original reports.

345 Overall, we estimate the epidemic covered approximately $245,750 \mathrm{~km}^{2}$, using a minimum convex 346 polygon around all outbreak locations in our dataset. We acknowledge the actual land area was likely less 347 due to the non-contiguous spread reported by Davies, where true involvement of the land was not 348 spatially contiguous.

\section{DISCUSSION}

352 The unusual, unprecedented nature of the epidemic and how it became manifest in Rhodesia was the 353 subject of several papers. Davies emphasized the pattern of case counts in relation to seasonal 354 precipitation and tabanid (horsefly) counts (Figure 9) ${ }^{30}$ as a way of explaining the abruptness and 355 magnitude of the epidemic's spread possibly due to a combination of flooding and biting arthropods. ${ }^{5}$

356 This hypothesis was supported by multiple accounts by patients of having received a painful insect bite 
357 that later evolved into an eschar. ${ }^{4}$ However, there was no report of extreme meteorological conditions or 358 tabanid activity, however early 1978 was considered wetter than usual. There were no available 359 observations of tabanids biting cattle, however this may be assumed because tabanid blooms coincided 360 with the appearance of bovine anthrax. ${ }^{31}$ This initial observation has been met with a high degree of 361 debate over the years, with Kobuch et al remarking in 1989:

In Zimbabwe, the Tabanidae multiply seasonally during the rainy summer months (October to April). They will settle and feed on carcasses of dead animals or on open wounds of the living and they readily bite humans, horses, cattle, and other livestock. The data for the tabanids derive from a detailed study carried out in 1973 and it has to be assumed that similar patterns occur annually. While the rise-fall-rise patterns of tabanid species counts parallel the numbers of anthrax cases, the concept of an association between biting flies and the incidence of anthrax remains a subject of controversy. ${ }^{25}$

374

In 2004, blowflies were later shown to be an important vector in Rhodesia during the context of a multispecies epidemic. The evidence that supported this hypothesis was the observation that browsers (kudu) versus grazers were predominantly infected. This was due to blowflies feeding on anthrax-infected carcasses and then regurgitating live Bacillus anthracis on leaves at grazing height versus directly on the ground. ${ }^{15}$ Davies suggested the possible involvement of vultures in the transmission cycle, but this 
382 An alternate hypothesis was proposed by Meryl Nass, an American physician living in Zimbabwe at the 383 time who suggested the epidemic was propagated intentionally. She emphasized the unusual features of

384 the epidemic: large numbers of cases, geographic extent and involvement of areas that had never reported 385 anthrax before, lack of involvement of neighboring countries, specific involvement of the Tribal Trust

386 Lands versus European-owned agricultural land, and coincidence with an ongoing civil war. ${ }^{33}$ Witness

387 testimony from Tribal Trust Land inhabitants revealed a belief that "poisoning" by anthrax occurred

388 during the Counterinsurgency. ${ }^{34,35}$ Other authors provided testimony of deliberate anthrax releases

389 during the Counterinsurgency by Rhodesian and South African forces and speculated this activity was a 390 progenitor to South Africa's Project Coast, a biological weapons program. ${ }^{36,37}$ Despite others supporting

391 Nass' provocative debate ${ }^{38,39}$, no additional evidence has been offered to support this assertion.

392

393 A review of Figure 8 shows the epidemic generally avoided what Rhodesian forces considered Vital 394 Asset Ground during the Counterinsurgency however this observation was not universal. Vital Asset 395 Ground was generally defined as the center ovoid area of the country consisting of non-Tribal Trust, 396 European-owned land that ran from the southwest to the northeast. Joseph Nkomo's Soviet and Cuban397 backed ZIPRA armed forces were based to the west of Rhodesia, and began an escalation of attacks into 398 Matabeleland Province in 1978. In September 1978, a Soviet ground missile launched by ZIPRA forces 399 downed a civilian Air Rhodesia Viscount. Rhodesian media had reported that 10 of 18 survivors were 400 massacred on the ground by ZIPRA forces after the plane crashed, provoking a dramatic escalation in the 401 conflict. Soon thereafter, Maoist ZANU forces led by Robert Mugabe in turn escalated their attacks to 402 the east in Mashonaland Province. All of Rhodesia was subsequently involved in conflict with ZANLA 403 and ZIPRA guerilla forces that expanded their infiltration of the country from 8,952 to 11,183 personnel 404 (25\% increase) from December 1978 to January 1979. Infiltration routes spanned nearly every sector of 405 border in the country during this period and exploited access to the resources and support of the Tribal 406 Trust Lands as the insurgents ranged inwards towards the center of the country. ${ }^{28}$ The first phase of the 407 epidemic of anthrax began in November 1978 in Nkai, Matabeleland Province. The second phase of the 
408 epidemic, which was focused on Mashonaland Province, escalated dramatically in late 1979.3-5 The

409 Kuldorff statistic identified clusters of high anthrax activity in November and December 1978, September 410 1979, and January and February 1980.

411

412 Bovine and human anthrax had been reported in years past in Nkai, Que Que, and many other districts

413 involved in the epidemic. ${ }^{3}$ There are notable observations, however, that confound an explanation

414 regarding the unusual nature of this epidemic within the context of modern history:

415

416 - There was no report of anthrax in wildlife in Rhodesia / Zimbabwe until 2004. ${ }^{15}$

417 - No point source of anthrax was identified. ${ }^{25}$

418 - As of the date of our study, the volume of human anthrax cases reported here has not been

419 previously reported anywhere in the world.

420 - The scale of cases in cattle and humans and associated morbidity and mortality was suggestive of 421 low indigenous herd immunity. ${ }^{1,40}$

422 - Anthrax was previously not observed to transmit so pervasively in Rhodesia as far back as 1898 ,

423 when neither antibiotics or vaccines were available. ${ }^{12}$ This is despite the well documented

424 presence of both cattle and humans dating back to the early $1800 \mathrm{~s}^{2}$

425 - There has, to-date, been no recorded instance in global history of a combined bovine-human

426 anthrax epidemic of this magnitude attributed to an interruption of a cattle vaccination control

427 program.

428 - The observation of all clinical forms of anthrax within such a small time period has not been

429 previously documented in world history. ${ }^{3-5,7}$

430 - There were no reports of unusual population densities of tabanid or other families of candidate

$431 \quad$ vector arthropods present at the time. ${ }^{5}$

432 - There were no reports of grossly unusual meteorological activity at the time. ${ }^{17,25,41}$ 
433

434

435

436

437

438

439

440

441

442

443

444

445

446 447 Figure 8).

448

449

450

451

452

453

454

455

456

457

458

.

- There was no confirmatory evidence to explain the apparent geotemporal and non-contiguous spread observed with cattle and human cases reported during the epidemic.

- Multiple physicians, veterinarians, public health and biodefense professionals focused their

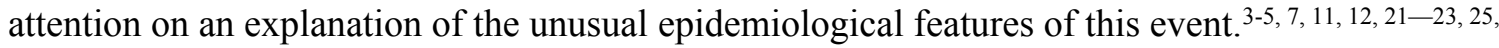
31,33

- Multiple independent sources reported the use of chemical and biological weapons by Rhodesian forces. ${ }^{33-39}$ The appearance and clustering of anthrax in humans geotemporally mirrored escalation in conflict with ZIPRA and ZANLA forces. ${ }^{28}$

The sole possible exception to some of the above observations is the purported anthrax epidemic of 1770 in Haiti (then-Saint Domingue) that killed 15,000 indigenous and European people over a period of six weeks. The dominant clinical form of anthrax in Haiti was hypothesized to be gastrointestinal following the distribution of contaminated meat. ${ }^{42}$ In comparison, the Rhodesia epidemic occurred over a longer time frame, with involvement of non-contiguous areas, and with several waves of transmission (see

Contiguous, localized spread of anthrax in humans was observed to be due to a stressed African indigenous population slaughtering their cattle for food and engaging in local commerce with the contaminated meat. ${ }^{3,4,15}$ This was a contributing factor in the context of food insecurity during the war. The areas of anthrax involvement spanned multiple indigenous tribes across areas of intense conflict where the roadways were mined and travel was restricted for the general public. ZANLA and ZIPRA forces often fought each other as well as Rhodesian forces and were supported by different indigenous communities. ${ }^{15}$ In all of the district hospitals, reported human cases had slaughtered local cattle prior to their illnesses, where the majority of cases were initially cutaneous presentations. ${ }^{3-5}$ An apparent high fatality rate among cattle is suggestive of either exposure through inhalation or gastrointestinal routes. ${ }^{1}$ It remains unclear how the cattle were infected across such vast geography. It may be hypothesized that 
459 transport of live cattle, as was often observed when indigenous African owners sought to avoid official

460 scrutiny during peacetime, could have also contributed to spread. We propose this was unlikely to

461 account for the distances of the different novel foci that appeared in the various locations of the country

462 due to a combination of 1) tribal boundaries and ownership and 2) restrictions to population movement

463 due to land mines and enforcement of movement controls by authorities during the war. Therefore, while

464 local trade of infected meat or cattle movement likely played some role in human exposures, it does not

465 explain the spread of anthrax across such vast geography.

466

467 In summary, one hypothesis is emergence and subsequent expansion of anthrax from a combination of

468 endemic ecological foci and increasing cattle population density in the context of poor veterinary control

469 practice from 1967 to $2006^{27}$. Expansion was facilitated by a combination of seasonal meteorological

470 factors such as temperature and precipitation, along with possible inclusion of arthropod vectors. Under

471 this hypothesis, anthrax' expansion was an unfortunate outcome of the collapse of control measures

472 during the Counterinsurgency from which Zimbabwe has yet to fully recover.

473

474 The competing hypothesis is anthrax was endemic in Rhodesia prior to the Counterinsurgency, however 475 deliberate exploitation of the wartime environment through intentional release of anthrax occurred at 476 various times and locations in Rhodesia. Under this hypothesis, new endemic foci were created after 477 cattle were targeted by Rhodesian or South African forces. The collapse of control measures enabled

478 further spread, which was enhanced by seasonal meteorological factors with or without arthropod

479 vectoring. Current activity of anthrax in Zimbabwe now follows endemic seasonal patterns.

480

481 No definitive explanation to-date has been offered to explain the many unusual features of this epidemic.

482 We acknowledge that lack of data regarding several of the observations related to this epidemic provides

483 important sources of bias in this study. Despite the limitations of the data associated with this important

484 historical event, and in agreement with other authors ${ }^{27}$, we propose a need for further scrutiny of the 
485 etiology of this epidemic, which contributed to substantial human suffering and the destruction of a once-

486 vibrant national agricultural economy.

487

488

489 ACKNOWLEDGEMENTS

490

491 The authors would like to thank JCA Davies and GA Cross for their input and the reviewers of this

492 manuscript for their consideration.

493

494

495

REFERENCES

496

497

498

1. De Vos V and PCA Turnbull. Anthrax. Coetzer JAW and Tustin RC, eds. Infectious Diseases

499 of Livestock. Oxford, UK: Oxford University Press, 1788-1818.

500

2. Mwatwara W. A history of state veterinary services and African livestock regimes in colonial

501 Zimbabwe, c. 1896-1980. Dissertation presented for the degree of Doctor of Philosophy (History) in

502 the faculty of Arts and Social Sciences at Stellenbosch University. Available at

503 http://scholar.sun.ac.za/handle/10019.1/86424. Accessed on December 24, 2015.

504

3. Davies JCA. A major epidemic of anthrax in Zimbabwe (Part I). The Central African Journal of

505 Medicine, 1982. Vol. 28, No. 12, 291-98.

506

4. Davies JCA. A major epidemic of anthrax in Zimbabwe (Part II). The Central African Journal of Medicine,1983. Vol.29, No. 1, 8-12.

508

5. Davies JCA. A major epidemic of anthrax in Zimbabwe: the experience at the Beatrice Road

509 Infectious Disease Hospital, Harare. The Central African Journal of Medicine, 1985. Vol. 31, No. 9, $509 \quad 176-80$.

510 6. World Bank, 1986. Report No. 5878-ZIM: Zimbabwe Land Subsector Study. 
511 7. Turner M. Anthrax in humans in Zimbabwe. The Central African Journal of Medicine, 1980.

512 Vol. 26, No. 7, 160-61.

513 8. Whitlow JR. Land use, population pressure and rock outcrops in the tribal areas of Zimbabwe

$514 \quad$ Rhodesia. Zimbabwe Rhodesia Agricultural Journal, 1980. Vol. 77, No. 1, 3-11.

5159 . Whitlow JR. Environmental constraints and population pressures in the tribal areas of Zimbabwe.

516 Zimbabwe Rhodesia Agricultural Journal, 1980. Vol. 77, No. 4, 173-81.

517 10. Mossman SL and Mossman AS. Wildlife utilization and game ranching. IUCN Occasional

518 Paper No. 17. Morges, Switzerland: 1976.

519 11. Lawrence JA, Foggin CM, Norval RAI. The effects of war on the control of diseases of livestock 520 in Rhodesia (Zimbabwe). The Veterinary Record (Rhodesia), 1980. Vol. 107, 82-85.

521 12. MacAdam I. Putting anthrax into perspective. The Zimbabwe Rhodesia Science News, 1980. Vol.

$522 \quad 14$, No. $2,38-41$.

523 13. Roberts CJ, Chambers, PG. An outbreak of anthrax in the Mondoro Tribal Trust Lands. The

524 Central African Journal of Medicine, 1975. Vol. 21, No. 4, 73-76.

525 14. Mwenye KS, Siziya S, Peterson D. Factors associated with human anthrax outbreak in the

526 Chikupo and Ngandu villages of Murewa district in Mashonaland East Province, Zimbabwe. The

527 Central African Journal of Medicine, 1996. Vol. 42, No. 11, 312-15.

528 15. Clegg SB1, Turnbull PC, Foggin CM, Lindeque PM. Massive outbreak of anthrax in wildlife in

529 the Malilangwe Wildlife Reserve, Zimbabwe. Vet Rec. 2007 Jan 27;160(4):113-8.

530 16. Rhodesia 1:1,000,000 Land tenure map. 3rd ed. Salisbury, Maryland: Surveyor-General, 1978.

531 17. World Bank, 2015. Climate Change Knowledge Portal. Available at

532 http://sdwebx.worldbank.org/climateportal/index.cfm?page=country historical climate\&ThisRegion

$533 \quad$ =Africa\&ThisCCode=ZWE. Accessed on December 24, 2015.

534 18. Chikerema SM, pers. comm. 2016.

535 19. Kulldorff M. SaTScan User Guide For Version 9.4. February, 2015.

536 20. Kulldorff M, Athas W, Feuer E, Miller B, Key C. Evaluating cluster alarms: A space-time scan 
537 statistic and brain cancer in Los Alamos. American Journal of Public Health, 1998; 88:1377-1380.

538 21. Levy LM, Baker B, Meyer MP, Crosland P, Hampton J. Anthrax meningitis in Zimbabwe. The 539 Central African Journal of Medicine, 1981. Vol. 27, No. 6, 101-104.

540 22. Latif AS, Nathoo KJ. Scrotal anthrax in a child: a case report. Ann Trop Paediatr. 1983

$541 \quad$ Mar;3(1):47-9.

542 23. Jena GP Intestinal anthrax in man: a case report. Cent Afr J Med. 1980;26:253-4.

543 24. Meselson M, Guillemin J, Hugh-Jones M, Langmuir A, Popova I, Shelokov A, Yampolskaya O.

544 The Sverdlovsk anthrax outbreak of 1979. Science. 1994 Nov 18;266(5188):1202-8.

545 25. Kobuch, W. E., Davies, J., Fleischer, K., Isaacson, M. and Turnbull, P. C. B., 1990. A clinical

546 and epidemiological study of 621 patients with anthrax in western Zimbabwe, Proceedings of the

547 international workshop on anthrax, Salisbury Medical Bulletin, 68 (supplement), 34-38.

548 26. Anonymous. Rhodesian Anthrax Spreads. Daily News-Record. October 16, 1979.

549 27. Chikerema SM, Pfukenyi DM, Matope G, Bhebhe E. Temporal and spatial distribution of cattle

550 anthrax outbreaks in Zimbabwe between 1967 and 2006. Trop Anim Health Prod. 2012 Jan;44(1):63-

$551 \quad 70$.

552 28. Cilliers JK. Counter-Insurgency in Rhodesia. Kent: Croom Helm Ltd, 1985.

553 29. Turnbull TCP. Guidelines for the surveillance and control of anthrax in humans and animals.

554 Third edition. World Health Organization WHO/EMC/ZDI/98.6, 1998 [online]. Available from:

555 http://www.who.int/csr/resources/publications/anthrax/WHO EMC ZDI 98 6/en/. Accessed

$556 \quad$ December 24, 2015.

557 30. Phelps RJ and Vale GA. Seasonal flight periods of Tabanidae (Diptera) in Rhodesia. Journal of 558 the Entomological Society of Southern Africa, $1975 ; 38: 341$.

559 31. McKendrick DR. Anthrax and its transmission to humans. Cent Afr J Med. 1980 Jun;26(6):1265609. 
561 32. Mundy PJ, Brand FE. An investigation of vultures and anthrax in Southern Africa. Rhodesian

562 Veterinary Journal, 1978. Vol. 9, 36-39.

563 33. Nass M. Anthrax epizootic in Zimbabwe, 1978-1980: due to deliberate spread? Physicians for

564 Social Responsibility Quarterly, 1992. Vol. 2, No. 4, 198-209.

565 34. Alexander J, McGregor J, and Ranger T, Violence and memory: one hundred years in the 'dark

566 forests' of Matabeleland. Portsmouth, NH: James Curry, 144-5, 172-9.

567 35. White L. Poisoned food, poisoned uniforms, and anthrax: or, how guerillas die in war. Osiris. $568 \quad 2004 ; 19: 220-33$.

569 36. Gould C and Folb PI. Project Coast: Apartheid's Chemical and Biological Warfare Programme, $570 \quad$ United Nations Publications, 2002.

571 37. HE Purkitt and SF Burgess. The Rollback of South Africa's Chemical and Biological Warfare $572 \quad$ Program, 2001.

573 38. Mangold T, Goldberg J. Plague wars. 1st ed. New York: St. Martin’s Press, 1999.

574 39. Martinez I. Rhodesian anthrax: the use of bacteriological and chemical agents during the

575 liberation war of 1965-80. Indiana International and Comparative Law Review. 13(2): 447-479.

576 40. Cizauskas CA, Bellan SE, Turner WC, Vance RE, Getz WM. Frequent and seasonally variable 577 sublethal anthrax infections are accompanied by short-lived immunity in an endemic system. J Anim 578 Ecol. 2014 Sep;83(5):1078-90. doi: 10.1111/1365-2656.12207.

579 41. Unganai LS, Mason SJ. Spatial characterization of Zimbabwe summer rainfall during the period 580 1920-1996. South African Journal of Science, 2001. Vol. 97, 425-31.

581 42. Morens DM. Epidemic anthrax in the eighteenth century, the Americas. Emerg Infect Dis. 2002 582 Oct;8(10):1160-2.

583

584 
Figure 1 (on next page)

Microsoft Word - FIGURE 1.doc FIGURE 1. Historical anthrax human cases reported from 1926 to 1977. Vaccination for anthrax in cattle was not available until the mid-1950s. 

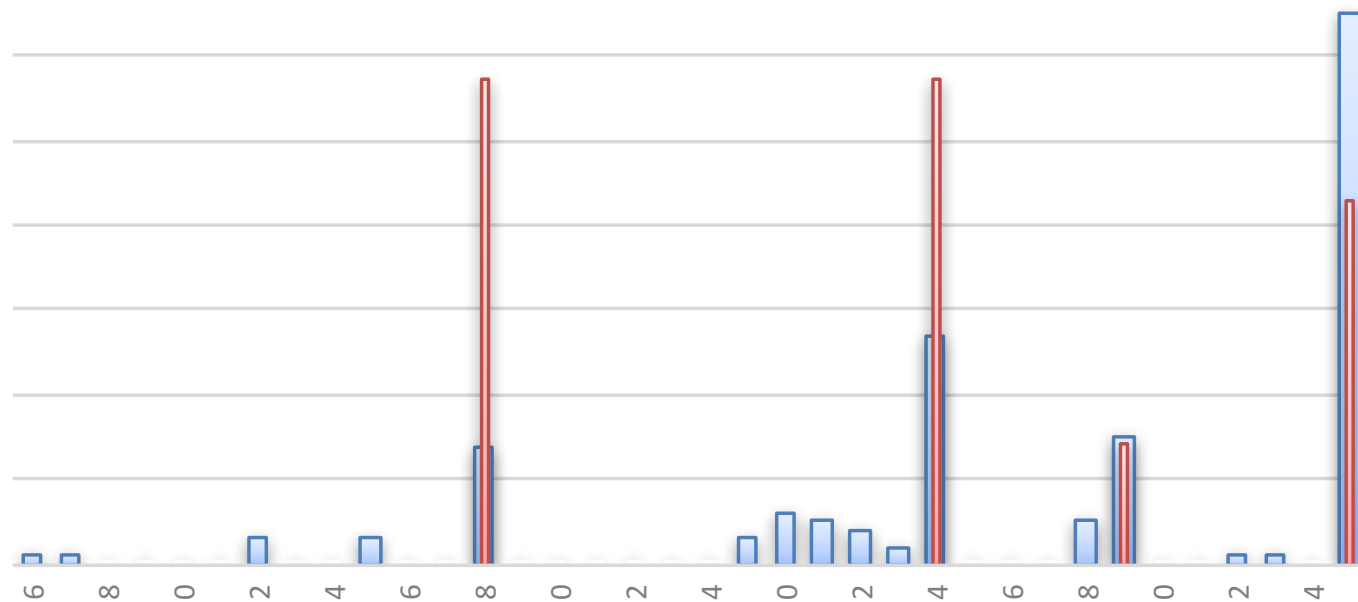

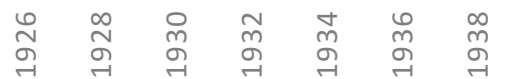


Figure 2 (on next page)

Microsoft Word - FIGURE 2. doc FIGURE 2. Rhodesian human anthrax cases from January 1979 to December 1980 for the provinces of Matabeleland, Midland, and Mashonaland. 
Anthrax Epidemic in Matabeleland, Midland, and Mashonaland

\section{Provinces, Rhodesia}

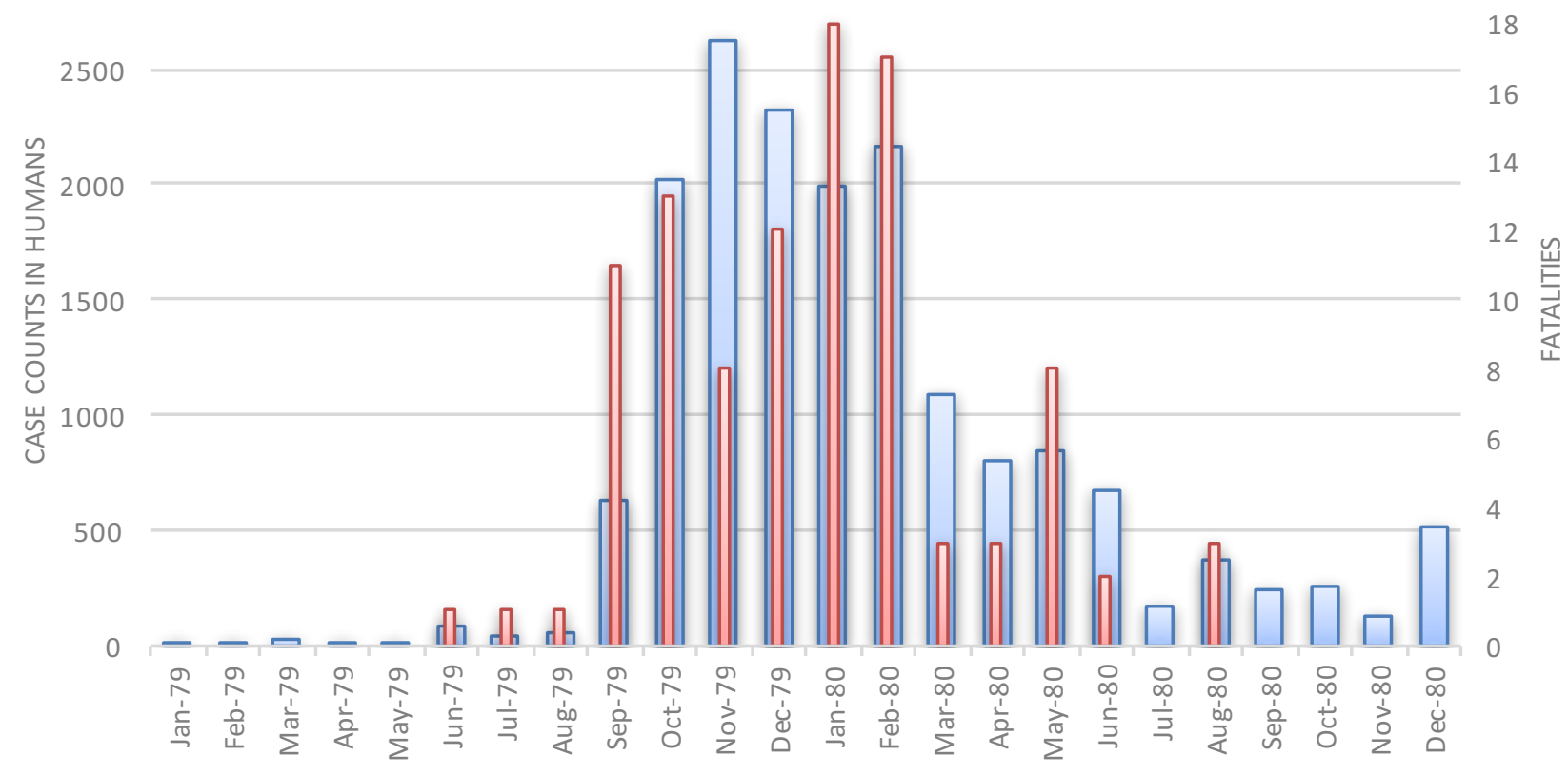


Figure 3 (on next page)

Microsoft Word - FIGURE 3.doc FIGURE 3. Rhodesia climatology based on data from 1960-80. The anthrax epidemic in Rhodesia began in cattle during the dry season, followed by a dramatic surge in human cases observed ahead of the peak of the rainy $s$ 


\section{Rhodesia Climatology (1960-80)}

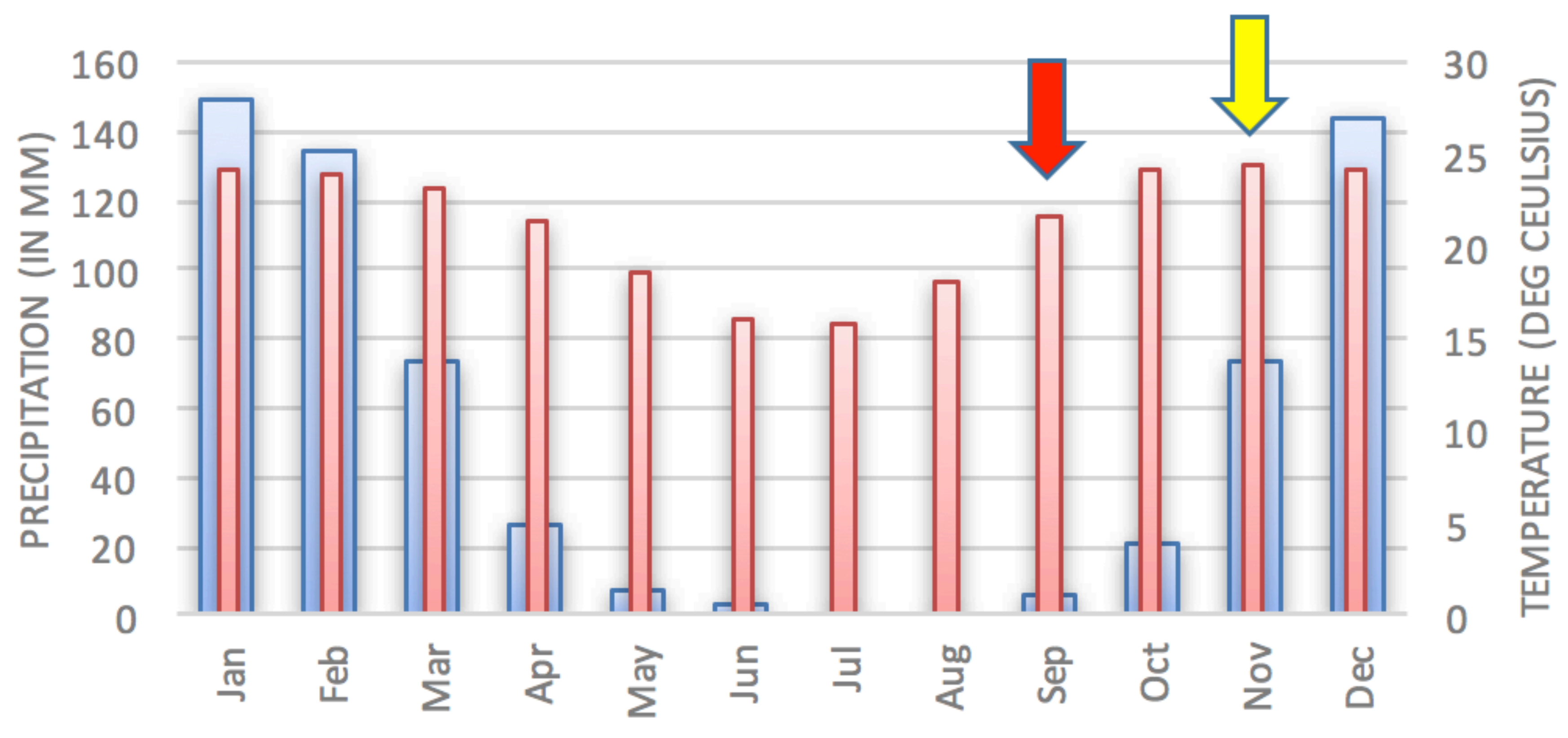

$\square$ Precipitation (in mm) $\quad \square$ Temperature (deg C) 
Figure 4 (on next page)

Microsoft Word - FIGURE 4. doc FIGURE 4. Human anthrax cases by province, noting the temporal shift in the peak of cases as the epidemic progressed across the country. A second wave of cases is observed in the data for Mashonaland Province. 


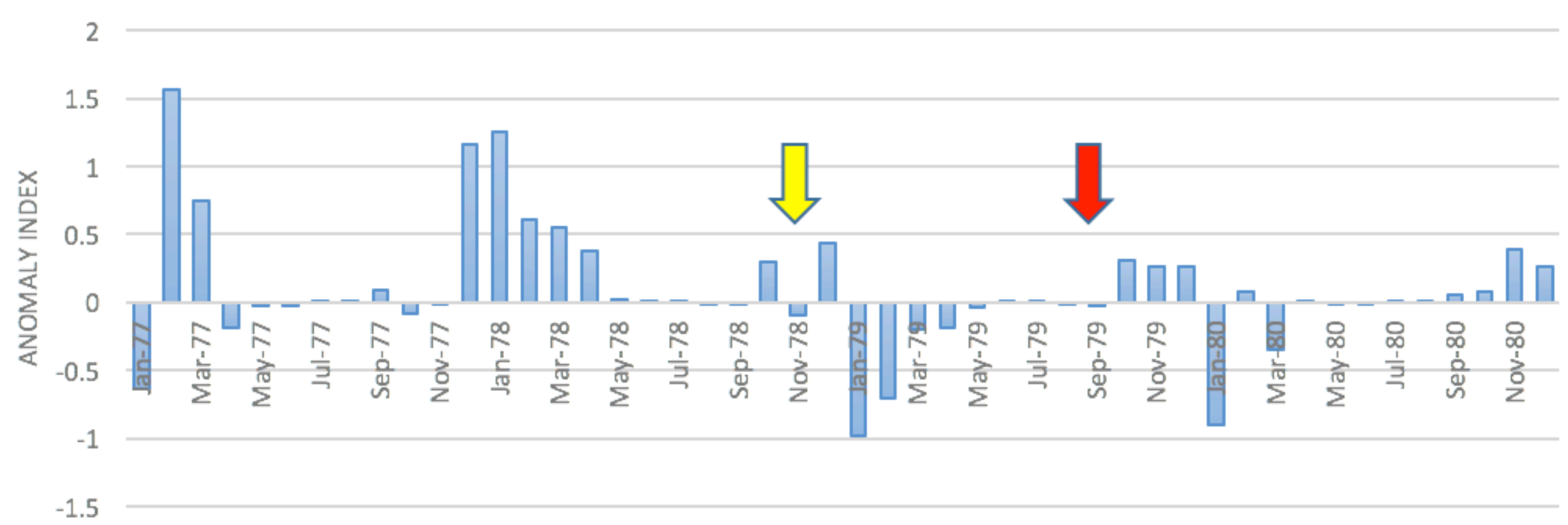

\section{Rhodesia Monthly Temperature Anomalies (1977-1980)}

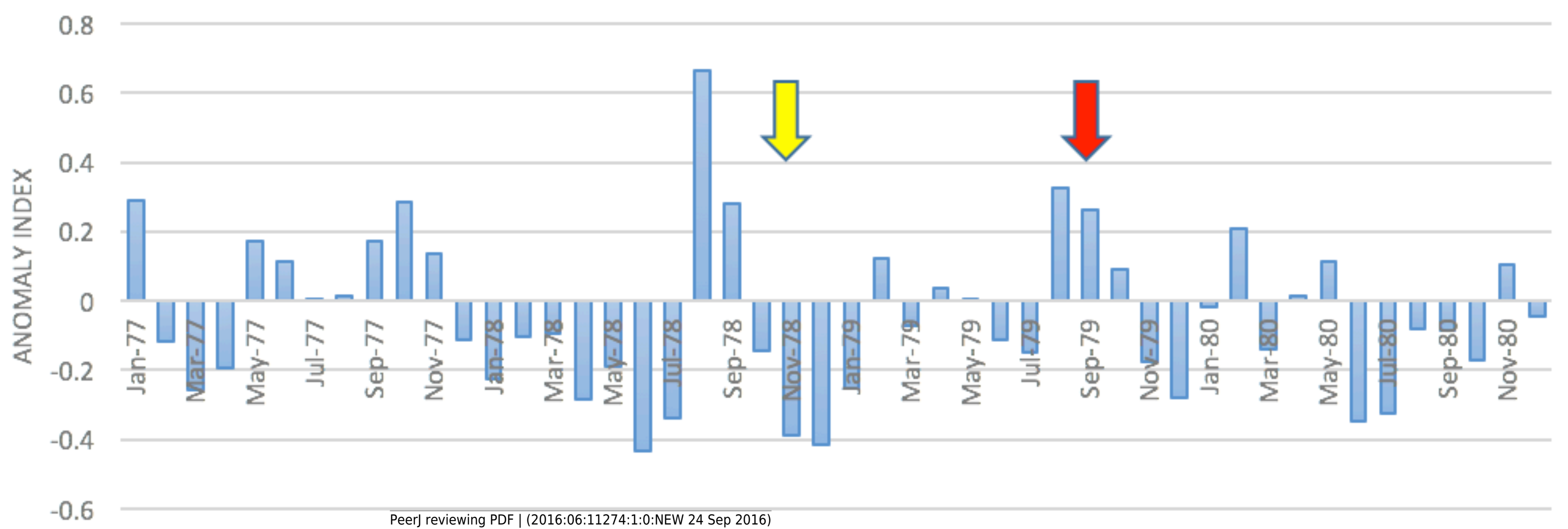


Figure 5 (on next page)

Microsoft Word - FIGURE 5.doc FIGURE 5. Human anthrax cases in Que Que District, which experienced a prolonged peak from October 1979 to February 1980. 
Anthrax in Matabeleland Provib6e,ript to be reviewed Rhodesia (Jan 1979-Oct 1980)

1200

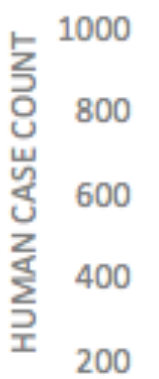

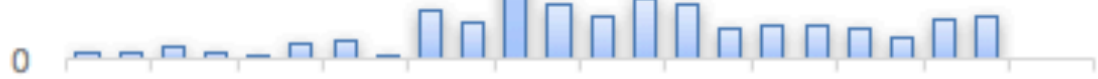

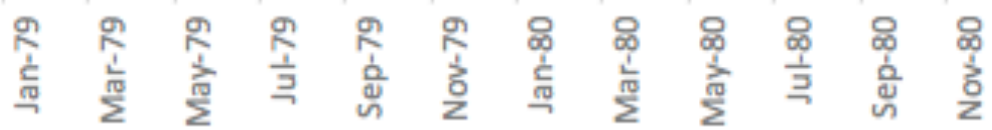

Anthrax in Midlands Province, Rhodesia (Jan 1979-Oct 1980)

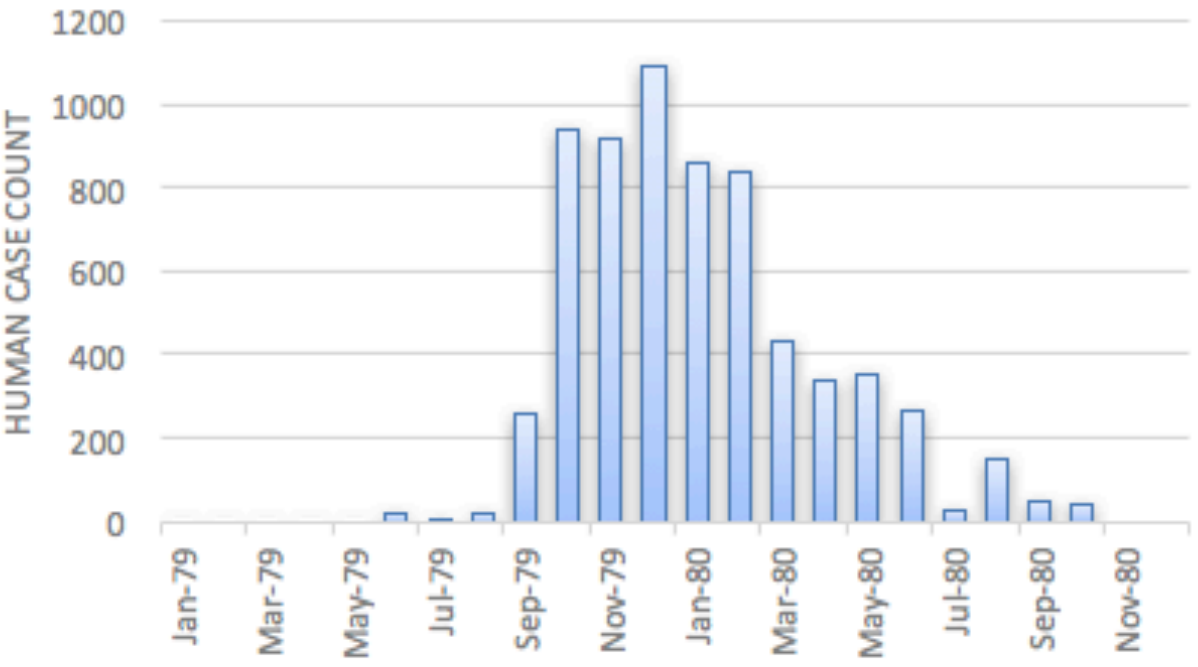

Anthrax in Mashonaland Province, Rhodesia (Jan 1979-Dec 1980)

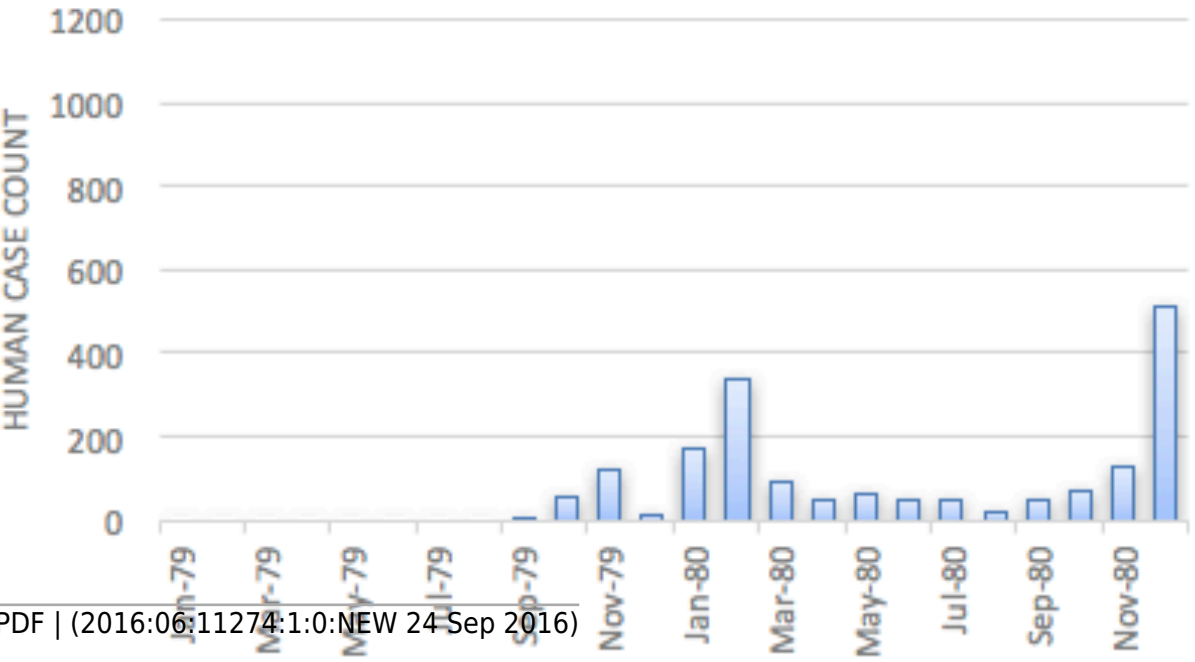


Figure 6 (on next page)

Microsoft Word - FIGURE 6.doc FIGURE 6. Human anthrax cases seen at the Beatrice Road Infectious Disease Hospital. This hospital, by March 1980, reported that anthrax was the leading reason for hospital admission. The facility experienced resou 


\section{Anthrax in Que Que District, Midlands Province, Rhodesia (Jun 1979-Oct 1980)}

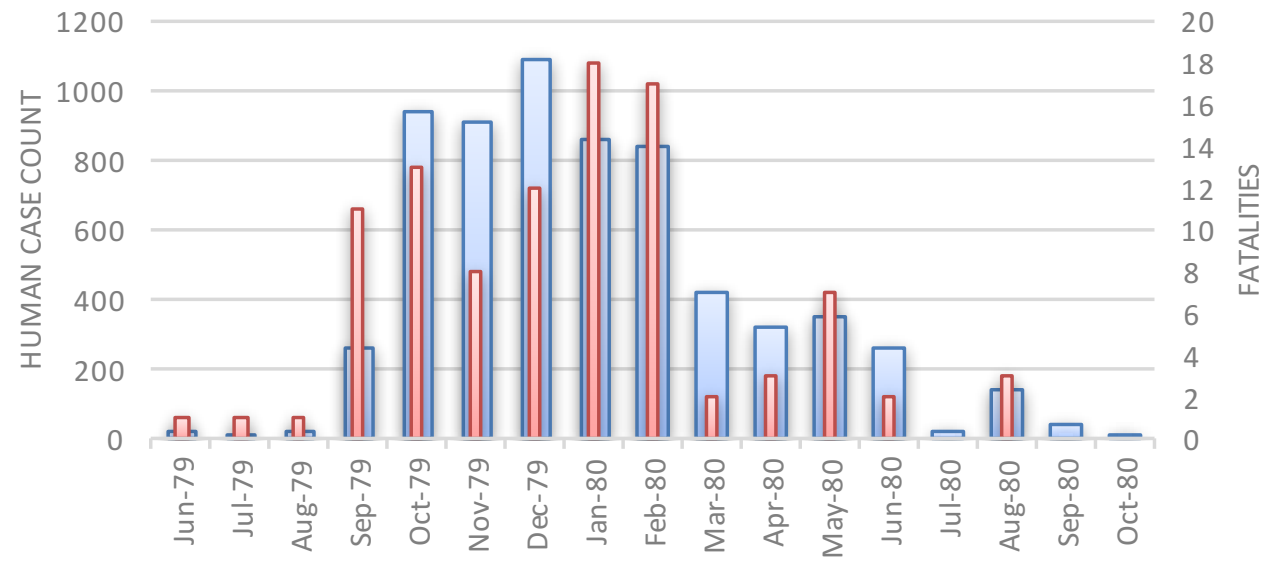

$\square$ Human Case Counts $\square$ Fatalities 
Figure 7 (on next page)

Microsoft Word - FIGURE 7.doc FIGURE 7. Geospatial time series progression of the anthrax epidemic in humans. The mean of outbreak coordinates is indicated as a centroid coordinate, where each time step is associated with spatial movement of that 
Anthrax Cases Seen at Beatrice Road Infectious Disease Hospital

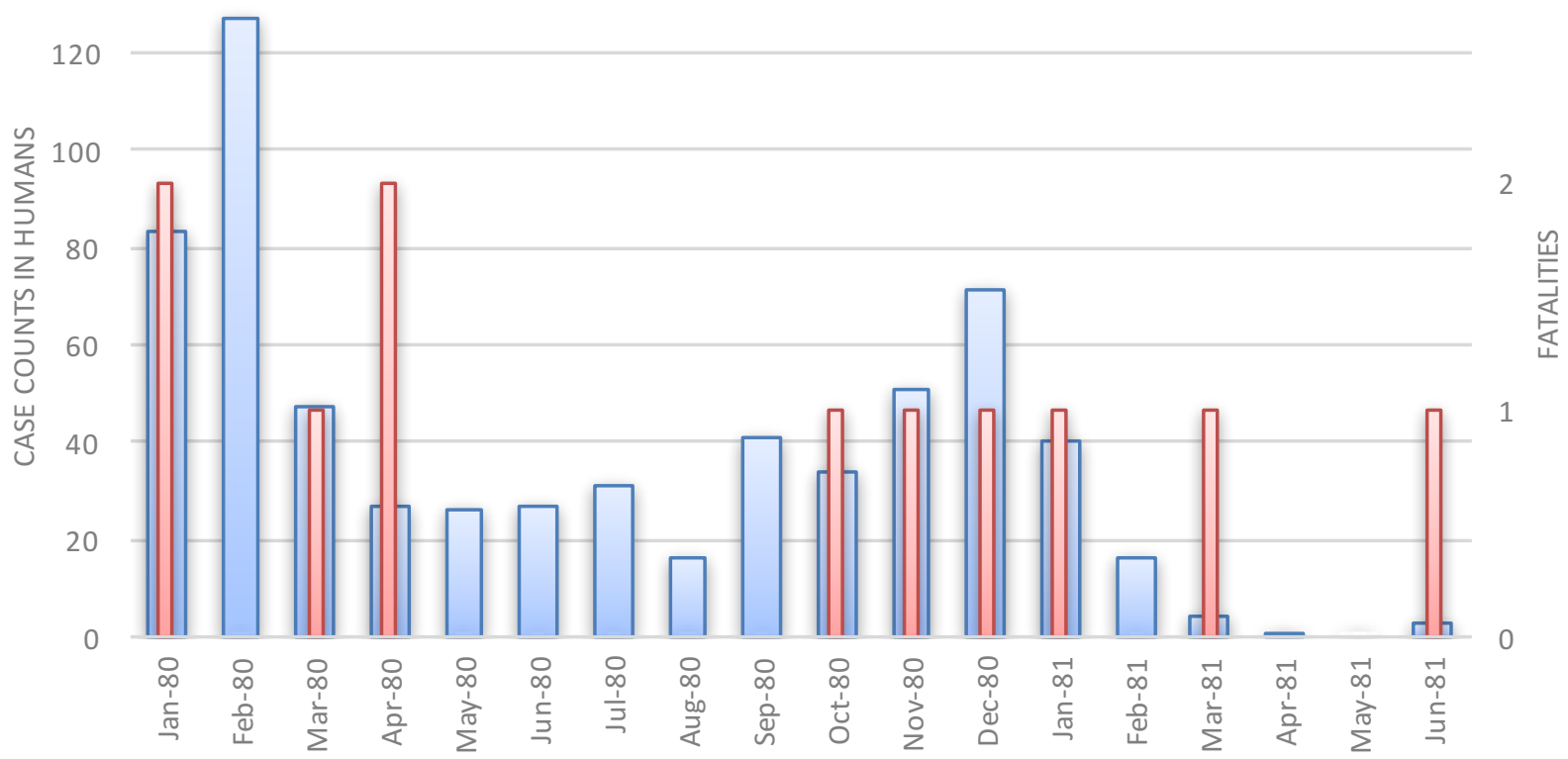

$\square$ Human Case Counts $\quad$ Fatalities 


\section{Table $\mathbf{1}$ (on next page)}

Microsoft Word - TABLE 1.doc TABLE 1. Results of the Kuldorff space-time permutation analysis. The first geospatial time cluster identified in the data was September 1979, which was statistically significant. The remaining clusters, while not sta 
$\frac{1}{2}$

\begin{tabular}{|c|c|c|c|c|c|c|c|c|}
\hline Cluster & Coordinates & Radius & Time Frame & Number of Outbreaks & Expected Outbreaks & Observed / Expected & Test Statistic & $\underline{\text { P-Value }}$ \\
\hline A & $18.999396 \mathrm{~S}, 28.901210 \mathrm{E}$ & $32.95 \mathrm{~km}$ & Nov-78 to Dec- 78 & 2 & 0.087 & 23 & 4.4 & 0.24 \\
\hline B & $18.469056 \mathrm{~S}, 29.444797 \mathrm{E}$ & $59.37 \mathrm{~km}$ & Sep-79 & 3 & 0.26 & 11.5 & 4.67 & 0.055 \\
\hline C & $17.507240 \mathrm{~S}, 30.975851 \mathrm{E}$ & $58.94 \mathrm{~km}$ & Jan-80 & 4 & 0.61 & 6.57 & 4.27 & 0.25 \\
\hline D & $20.916667 \mathrm{~S}, 28.466667 \mathrm{E}$ & $83.34 \mathrm{~km}$ & Feb-80 & 3 & 0.43 & 6.9 & 3.3 & 0.79 \\
\hline
\end{tabular}

3 TABLE 1. Results of the Kuldorff space-time permutation analysis. Statistical significant was defined by $\mathrm{P}<0.05$. The clusters identified were associated with non-significant, higher relative risk. ${ }^{19}$ 
Figure 8 (on next page)

Seasonal Tabanid Counts Versus Precipitation, 1973 
Seasonal Tabanid Counts Versus Precipitation, 1973
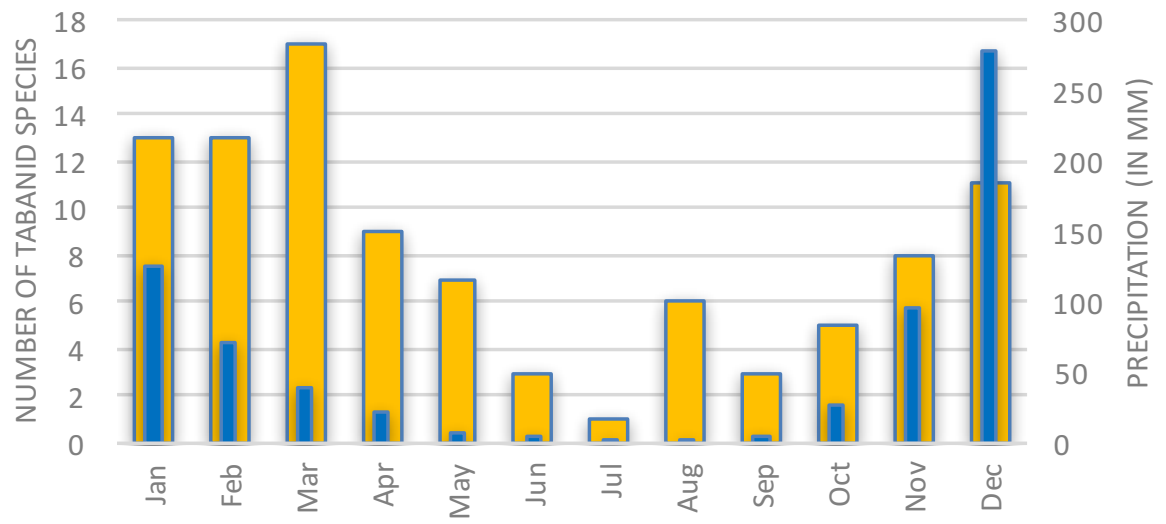

$\square$ Tabanid Species Count $\quad$ Precipitation (in mm) 